\title{
Theoretical Elucidation of the Mechanism of the Cycloaddition between Nitrone Ylides and Electron-deficient Alkenes
}

\author{
P. Merino*, T. Tejero and A. Díez-Martínez
}

Laboratorio de Síntesis Asimétrica. Departamento de Síntesis y Estructura de Biomoléculas. Instituto de Síntesis Química y Catálisis Homogénea (ISQCH).Departamento de Quimica Organica. Universidad de Zaragoza. CSIC. E-50009 Zaragoza. Aragón, Spain.

Fax: +34 976 509726; Tel: +34 876 553783;

pmerino@unizar.es

TOC
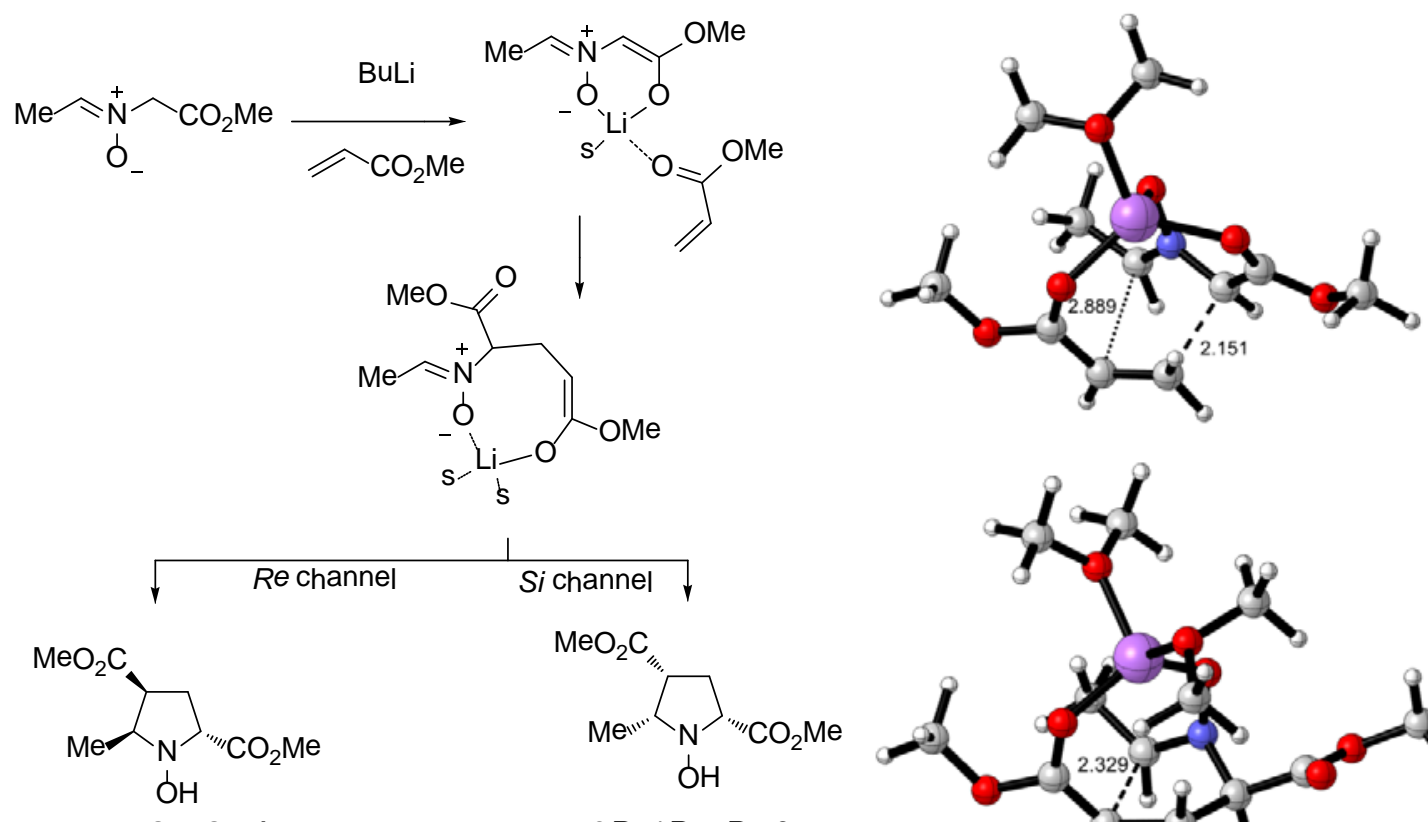

$\left(2 R^{\star}, 4 S^{*}, 5 S^{\star}\right)^{-4}$

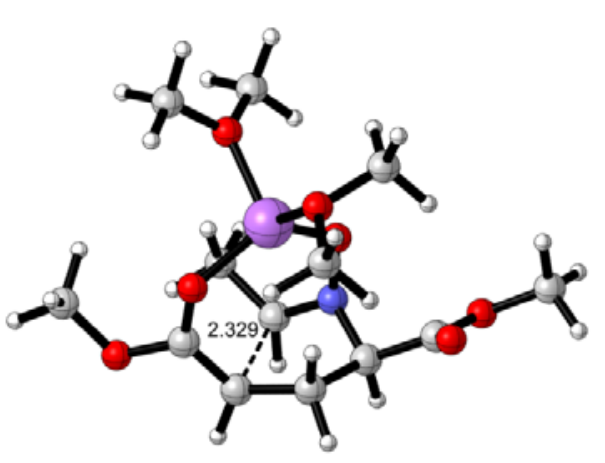




\begin{abstract}
A full theoretical study of the reaction between a novel type of ylides, i.e. nitrone ylides and alkenes has been carried out. Both concerted and polar stepwise mechanisms have been considered. Only the zwitterionic mechanism predicts correctly the experimentally observed adducts. Depending on the level of theory, the mechanism moves from concerted to polar stepwise, as demonstrated by the corresponding IRC analyses. The regio- and stereoselectivity of the reaction is well-explained for both mono- and disubstituted alkenes.
\end{abstract}




\section{Introduction}

Cycloaddition reactions are not necessarily pericyclic. ${ }^{1}$ Some discussion has accounted in the past concerning classical cycloadditions like Diels-Alder reactions, dipolar cycloadditions and related processes directed to consider the possibility of stepwise biradical mechanisms. ${ }^{2}$ In several cases, the biradical process has shown to be favored with respect to the corresponding concerted mechanism; this is the case, for instance, of some Diels-Alder reactions ${ }^{3}$ and dimerization of nitrile oxides. ${ }^{4}$

Alternatively, pseudopericyclic reactions have been defined by Birney and co-workers as a novel approach to explain apparently disallowed pericyclic reactions. ${ }^{5}$ Intermediate situations have been reported by Houk and co-workers ${ }^{6}$ and recently, we have reported a variation that could be considered as a bipseudopericyclic process. ${ }^{7}$ Cycloadditions can also take place through a polar stepwise mechanism. ${ }^{8}$ Indeed, typical concerted reactions can move to a polar mechanism when catalyzed with Lewis acids. ${ }^{9}$ Accordingly, there have been reported a variety of relevant studies considering concerted vs stepwise mechanisms (both biradical and polar) for a series of cycloaddition reactions. $^{10}$

Experimental proofs have been found in several cases by isolating and trapping intermediates ${ }^{9 \mathrm{~d}, 11}$ and in many other situations theoretical calculations fully supported the stepwise process vs the concerted one. ${ }^{3,8 b-g}$ Dipolar cycloadditions of azomethine ylides are representative of a dual situation. Depending on the substrates and/or the catalysts a concerted mechanism (Scheme 1, path a) or a stepwise one (Scheme 1, path b) operates. Domingo et al. reported a concerted mechanism for a trifluoromethyl thiomethyl ylides supported by DFT calculations ${ }^{12}$ although ELF analysis showed that the reaction was not pericyclic. ${ }^{13}$ A concerted mechanism has also been invoked for the 
reaction between azomethine ylides and simple substituted alkenes ${ }^{14}$ as well as for organocatalyzed reactions. ${ }^{15}$ On the other hand, Cossío and co-workers demonstrated a stepwise mechanism for the reaction of azomethine ylides with nitroalkenes by detecting an intermediate by NMR spectroscopy. ${ }^{16}$ The stepwise process was also supported by DFT calculations as in the case of a cycloaddition catalyzed by silver and copper complexes reported by Najera and co-workers. ${ }^{17}$ Moreover, Carretero and coworkers demonstrated the capability of azomethine ylides of behaving as nucleophiles (the first step of a stepwise cycloaddition) in the addition of such compounds to imines through a Mannich-type reaction. ${ }^{18}$ Isolation of intermediate Michael-type addition compounds at lower temperatures and further DFT calculations supported the stepwise mechanism. ${ }^{19}$

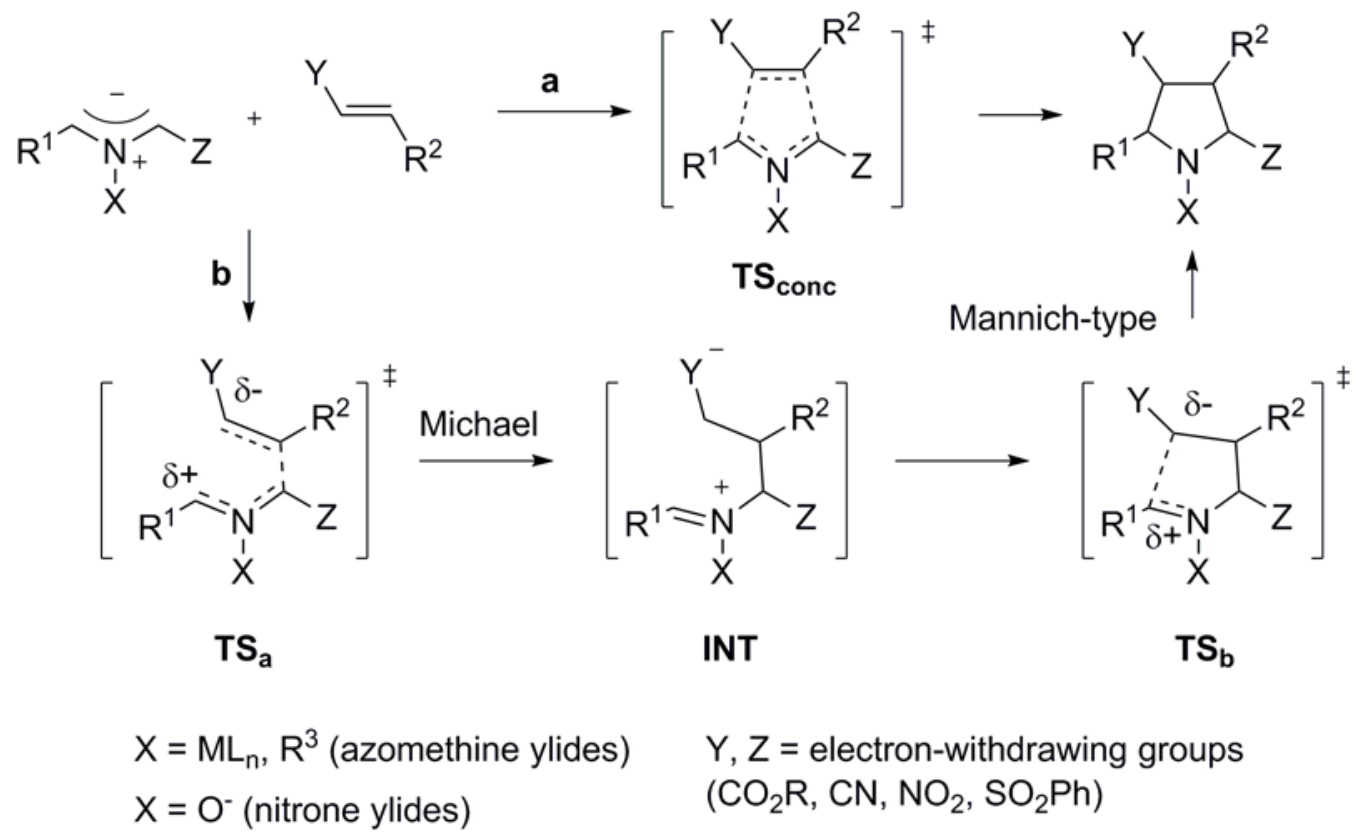

Scheme 1. Concerted (a) and stepwise polar (b) mechanisms for cycloadditions of azomethine ylides $\left(\mathrm{X}=\mathrm{ML}_{\mathrm{n}}, \mathrm{R}^{3}\right)$ and nitrone ylides $\left(\mathrm{X}=\mathrm{O}^{-}\right)$

In this context, we have recently reported a full experimental study on a new and different sort of ylides, i.e, nitrone ylides (Scheme $\left.1, \mathrm{X}=\mathrm{O}^{-}\right) .{ }^{20}$ Although they could be 
considered close to azomethine ylides because of the only difference resides in the oxygen atom replacing the carbon/metal atom attached to the nitrogen, their electronic structure is completely different. Nitrones are well-known dipoles in 1,3-dipolar cycloadditions, ${ }^{21}$ and they can behave as electrophiles in stepwise cycloadditions with electron-rich alkenes, as we have recently demonstrated for Mannich-type reactions with silyl ketene acetals. ${ }^{8 e, 8 g, 9 e}$

In the case of nitrone ylides the oxygen atom does not participate in the reaction and a different approach should be considered. In our previous experimental paper we isolated an open-chain intermediate for the reaction with methyl acrylate, demonstrating that the reaction followed a stepwise mechanism. On the other hand, we were not able of isolating the corresponding intermediate in the case of disubstituted alkenes (dimethyl maleate and fumarate). Since the stereochemistry of the alkene was conserved and the reaction showed to be stereospecific it might indicate that a concerted mechanism could operate in the case of disubstituted alkenes. To seed up some light on the mechanism of this reaction, the cycloaddition of nitrone ylides with electron-poor alkenes, we have carried out a full theoretical study of the reaction considering both mono- and disubstituted alkenes. In this paper we report our results on that study.

Computational methodology. Computations with density functional theory (DFT) were done using the exchange-correlation functional B3LYP ${ }^{22}$ and Thrular's functional M06-2X. ${ }^{23}$ Standard basis sets 6-31G(d) and 6-311G(d,p) were employed and diffuse functions were added in both cases. ${ }^{24}$ The nature of stationary points was defined on the basis of calculations of normal vibrational frequencies (force constant Hessian matrix). The optimizations were carried out using the Berny analytical gradient optimization method. ${ }^{25}$ Minimum energy pathways for the reactions studied were found by gradient 
descent of transition states in the forward and backward direction of the transition vector (IRC analysis), ${ }^{26}$ using the second order González-Schlegel integration method. ${ }^{27}$ The solvent effects modeled as a continuum model were considered for single points and full optimized highest level of theory employed using a relatively simple self-consistent reaction field $\left(\mathrm{SCRF}^{28}\right)$ based on the polarizable continuum model (PCM) of Tomasi’s group. ${ }^{29}$ The electronic energies in solution were obtained by adding the total electrostatic energies obtained from the PCM calculations to the electronic energies in vacuo. The PCM and solvent $=$ THF options were employed in the SCRF calculations. In addition, microsolvation of the lithium atom was considered by adding discrete molecules of dimethyl ether surrounding the lithium atom. ${ }^{30}$ Single point calculations were also carried out using B3LYP/6-31+G(d) geometries. Thus, for the purpose of comparison the following levels of theory were calculated: i) B3LYP/631+G(d); ii) M06-2X/6-31+G(d); iii) PCM=THF/B3LYP/6-311+G(d)// B3LYP/631+G(d); iv) PCM=THF/M06-2X/6-311+G(d)// B3LYP/6-31+G(d) and v) PCM=THF/M06-2X/6-311+G(d). All calculations were carried out with the Gaussian 09 suite of programs. ${ }^{31}$ Structural representations were generated using CYLview. ${ }^{32}$

All the discussions will be based on the highest level used (PCM=THF/M062X/6-311+G(d)). References to the other levels, whose values are provided in the supporting information, will be made when notable differences have been observed. Consistently with our previous experimental report, we have studied the reaction between nitrone $\mathbf{1}$ and methyl acrylate $\mathbf{2}$ to give $N$-hydroxypyrrolidines $\mathbf{3}$ and $\mathbf{4}$ with $\left(2 R^{*}, 4 R^{*}, 5 R^{*}\right)$ and $\left(2 R^{*}, 4 S^{*}, 5 S^{*}\right)$ relative configurations, ${ }^{33}$ respectively, in the presence of butyllithium in THF as a solvent (Scheme 2). 


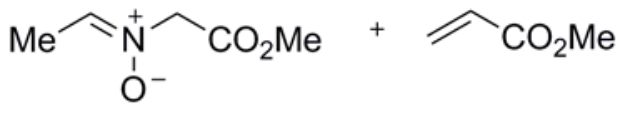

1

2

BuLi $\downarrow$ THF

$\mathrm{MeO}_{2} \mathrm{C}$

$\mathrm{Me}^{\prime \prime} \sum_{\substack{\mathrm{N} \\ \mathrm{OH}}}{ }^{\prime \prime} \mathrm{CO}_{2} \mathrm{Me}$



$\left(2 R^{*}, 4 R^{*}, 5 R^{\star}\right)-3$

major

$\left(2 R^{*}, 4 S^{*}, 5 S^{*}\right)-4$

minor

Scheme 2. Cycloaddition reaction between 1 and 2.

\section{Results and Discussion}

The first irreversible step of the reaction illustrated in Scheme 2 is the proton abstraction in nitrone $\mathbf{1}$ by butyllithium to form the corresponding nitrone ylide 5 (Scheme 3). Once the ylide is formed two different approaches can be considered: i) A direct approach (Scheme 3, path a) through a concerted transition state TS-c leading to the final product $\mathbf{P R}$ and ii) an initial Michael attack (Scheme 3, path b) of the nitrone ylide to methyl acrylate $\mathbf{2}$ through TS-s1 to form intermediate IN1, followed by an intramolecular Mannich-type reaction through TS-s2 to yield product PR. 




Scheme 3. Concerted and stepwise mechanisms for the cycloaddition of nitrone ylide 5 with methyl acrylate 2 . (s=solvent)

Direct approach. There are three possible initial transition states for a direct approach of methyl acrylate $\mathbf{2}$ to ylide $\mathbf{5}$ corresponding to three alternate dispositions of the two reagents ( 1 antiperiplanar and 2 gauche). This makes a total of 12 transition structures to be calculated since two different approaches are possible for the planar acrylate and two conformations (s-cis and s-trans) are possible for the same compound. From these twelve orientations four of them corresponding to gauche orientations could lead to concerted transition states TS1 - TS4 (Figure 1). From the other eight approaches we discarded four of them because they present significant unfavorable steric interactions. 
From the remaining four transition structures TS5 - TS8 only one did not present favorable interactions between the lithium atom and the carbonyl oxygen. Thus we located TS1 - TS8 illustrated in Figure 1.<smiles>C=CC(C)=O</smiles>

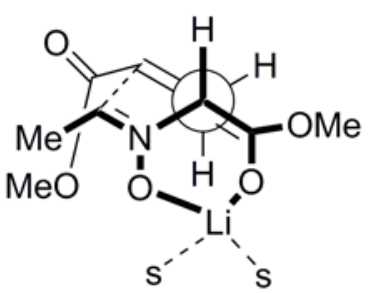

TS1 0.44<smiles>COC(=O)c1c2ccc(OC)c1O[Al](S)(S)O2</smiles>

TS3 0.00

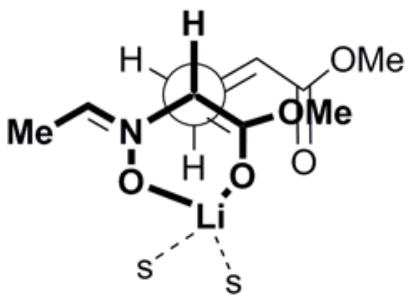

TS5 6.42

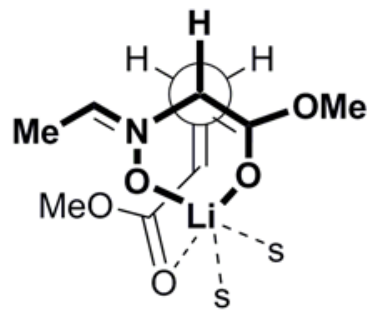

TS7 10.98<smiles></smiles>

TS2 3.38<smiles>COC(=O)c1c2ccc(OC)c1O[Si](S)(S)O2</smiles>

TS4 3.36

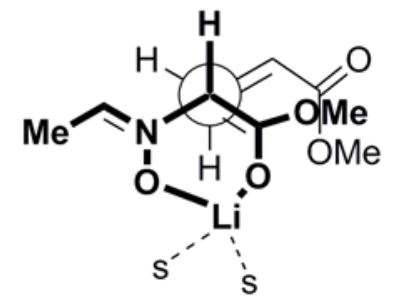

TS6 3.31

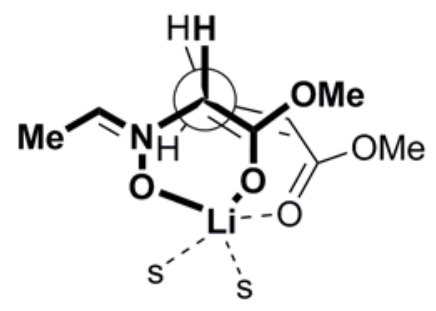

TS8 4.99

Figure 1. Transition structures corresponding to the direct approach between nitrone ylide 5 and methyl acrylate $\mathbf{2}$ (relative free energies calculated at PCM=THF/M062X/6-311+G(d,p) level of theory are indicated in $\mathrm{kcal} / \mathrm{mol})$. 
All the levels of theory studied showed TS1 and TS3 as the most stable having significant differences (more than $3 \mathrm{kcal} / \mathrm{mol}$ ) with the rest of TSs. The endo approach corresponding to TS1 is the most stable for all the levels studied with the exception of the highest one which showed TS3 to be $0.47 \mathrm{kcal} / \mathrm{mol}$ more stable. In this level, the calculated energy barriers for TS1 and TS3 were 14.69 and $14.22 \mathrm{kcal} / \mathrm{mol}$, respectively. The geometries of TS1 and TS3 are given in Figure 2.

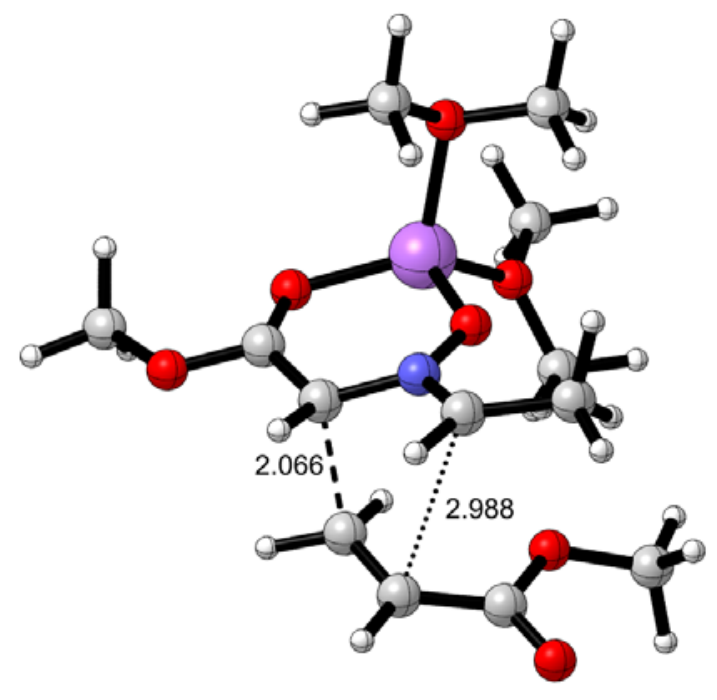

TS1

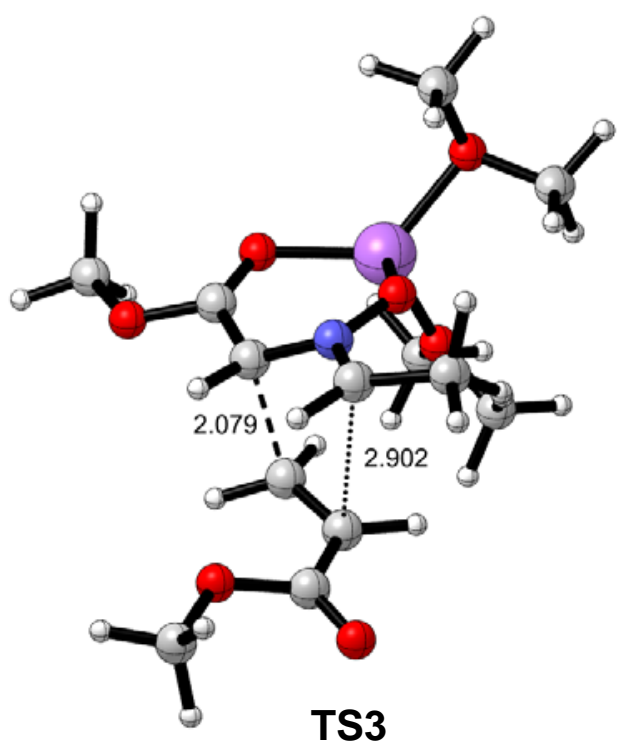

TS3

Figure 2. Transition structures corresponding to the direct approach between nitrone ylide 5 and methyl acrylate 2 optimized at PCM=THF/M06-2X/6-311+G(d,p) level of theory (distances are given in amstrongs).

The forming C2-C3 bonds are 2.066 and 2.079 $\AA$ for TS1 and TS3, respectively. The distances between C4 and C5 are 2.988 and $2.902 \AA$ for TS1 and TS3, respectively. These data point out to a very asynchronous concerted reaction. However, the frequency analysis -regarding the only negative frequency found for such TSs- was not definitive to identify the reaction as concerted. The corresponding IRC analysis for TS3 at M06-2X/6-31+G(d) level showed a concerted process starting in the reagents (nitrone $\mathbf{1}$ 
and methyl acrylate 2) and finalizing in the corresponding coordinated $\mathrm{N}$ -

hydroxypyrrolidine. ${ }^{34}$ On the other hand, an identical IRC analysis for TS1 at the same level of theory showed $\mathbf{5}$ and $\mathbf{2}$ as the starting point but IN1 as the final one. Moreover, although TS3 leads to the major isomer $\left(2 R^{*}, 4 R^{*}, 5 R^{*}\right)$ observed experimentally, TS1 predicted the obtention of $\left(2 R^{*}, 4 S^{*}, 5 R^{*}\right)$ isomer, whereas the minor isomer observed experimentally was that having the $\left(2 R^{*}, 4 S^{*}, 5 S^{*}\right)$ configuration (Scheme 4$)$. At this point, it was evident that the direct approach cannot be considered as the correct one. Notably, IRC analyses of both TS1 and TS3 at the highest PCM=THF/M06-2X/6-311+G(d,p) level showed the reaction as a stepwise process finalizing in the corresponding intermediate IN1. ${ }^{32}$ Accordingly, the interaction between C4 and C5 in the transition states leading to distances of 2.988 and $2.902 \AA$ can be considered as strictly electrostatic and it does not represent a forming bond in agreement with previously reported anionic stepwise [3+2] cycloadditions. ${ }^{35}$

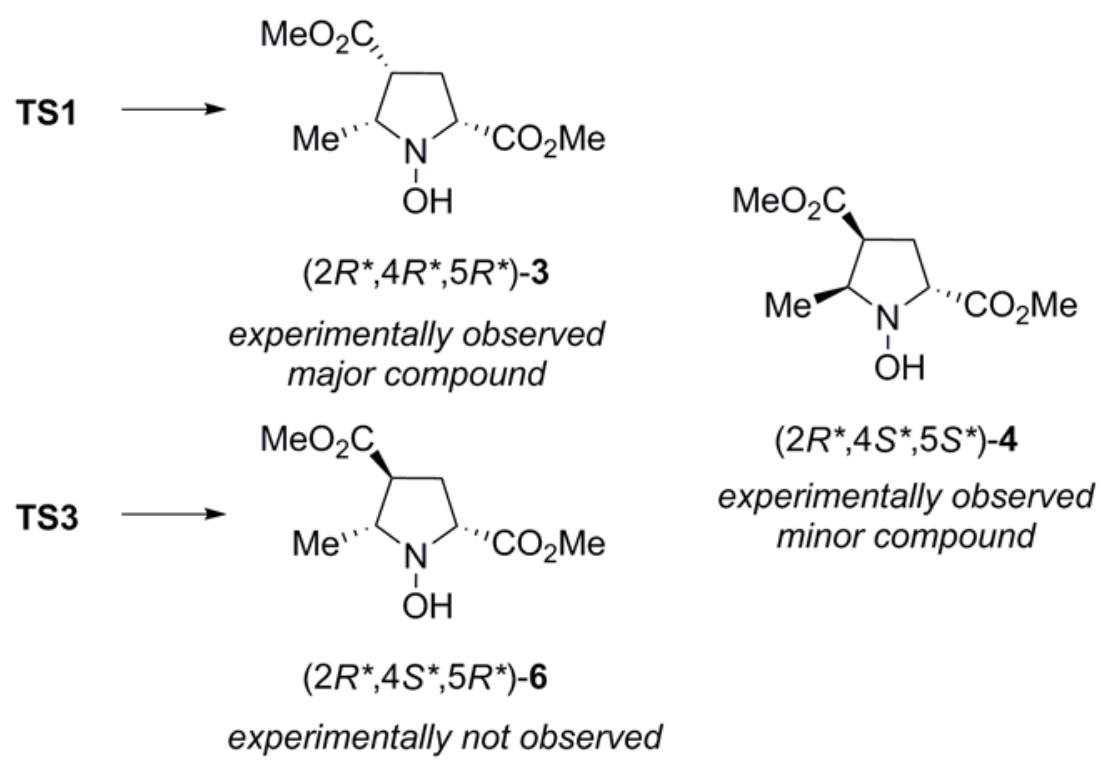

Scheme 4. Predicted products for a concerted mechanism and those observed experimentally. 
With this result in hand it is possible to conclude that the reaction is stepwise and further evolution of intermediate IN1 should involve the coordination of the formed enolate to the lithium atom through exchange of i) a solvent molecule to form intermediate IN2 (Figure 3), ii) the other ester carbonyl to form IN3 or iii) the nitrone oxygen to form IN4. Among these complexes IN4 can be discarded since for the second step, consisting of an intramolecular Mannich-type addition, activation of the nitrone by means of lithium coordination is required as we demonstrated both experimentally and theoretically. $^{8 \mathrm{e}, 9 \mathrm{e}}$

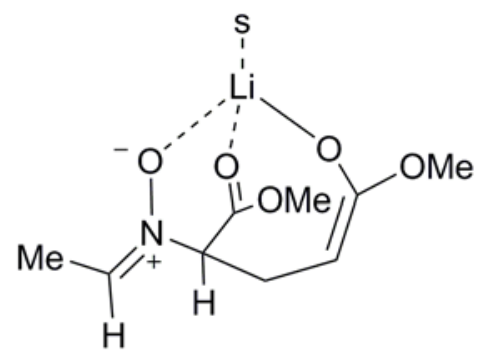<smiles>C/C=[N+]1\O[Al](S)(S)O/C(OC)=C\C[C@H]1C(=O)OC</smiles>

IN3

IN2<smiles>C/C=[N+](\[O-])[C@H]1CC=C(OC)O[Si](S)(S)OC1OC</smiles>

IN4

Figure 3. Plausible intermediates in the stepwise mechanism.

At this point, it seems more plausible that coordination between methyl acrylate and the lithium atom takes place before the initial Michael addition thus increasing the electrophilicity of the Michael acceptor. This approach, discussed in the next section, will allow explaining not only the formation of intermediates IN2 and IN3 but also their further cyclization as well as the observed experimental results.

Stepwise mechanism. Previous work from this laboratory ${ }^{36}$ demonstrated that nucleophilic additions of organometallic reagents to nitrones take place through the 
formation of an initial complex between the nitrone and the organometallic reagent. ${ }^{37}$ Moreover, it has also been demonstrated that coordination of the metal atom to the nitrone oxygen is required in order to increase the electrophilic character of the nitrone carbon. ${ }^{9 \mathrm{e}}$ In a similar way and advancing a second step consisting of a Mannich-type addition to nitrones $^{8 \mathrm{~g}}$ (see below) it is possible to consider the initial formation of complex 7 between ylide 5 and methyl acrylate 2 (Scheme 5, R=H). The formation of complex 7 takes place without energy barrier and activates the double bond towards the initial Michael attack. This complex leads to intermediate IN2 through TS9 in which the lithium atom keep coordinated both ester moieties as well as the nitrone oxygen. Further evolution of IN2 towards the product is rather limited because of the rigidity of the model. Thus, transformation of IN2 into PR1, precursor of the major product observed experimentally, is only possible through TS10. We located all the stationary points illustrated in Scheme 5. A full energy diagram is given in Figure 4. Notably, TS9 is $5.53 \mathrm{kcal} / \mathrm{mol}$ lower in energy than TS3, thus demonstrating that the pathway illustrated in Scheme 5, involving previous coordination of methyl acrylate, is preferred. The activation free energy associated with the conversion of the reagents into IN2 is $8.69 \mathrm{kcal} / \mathrm{mol}$. The intermediate IN2 is located $0.32 \mathrm{kcal} / \mathrm{mol}$ below the reagents and the energy barrier for the second step of the reaction is $13.27 \mathrm{kcal} / \mathrm{mol}$ to form the adduct PR1, which is located $15.72 \mathrm{kcal} / \mathrm{mol}$ below the reagents. Consequently, the rate-limiting step for this process is the intramolecular Mannich-type reaction. 

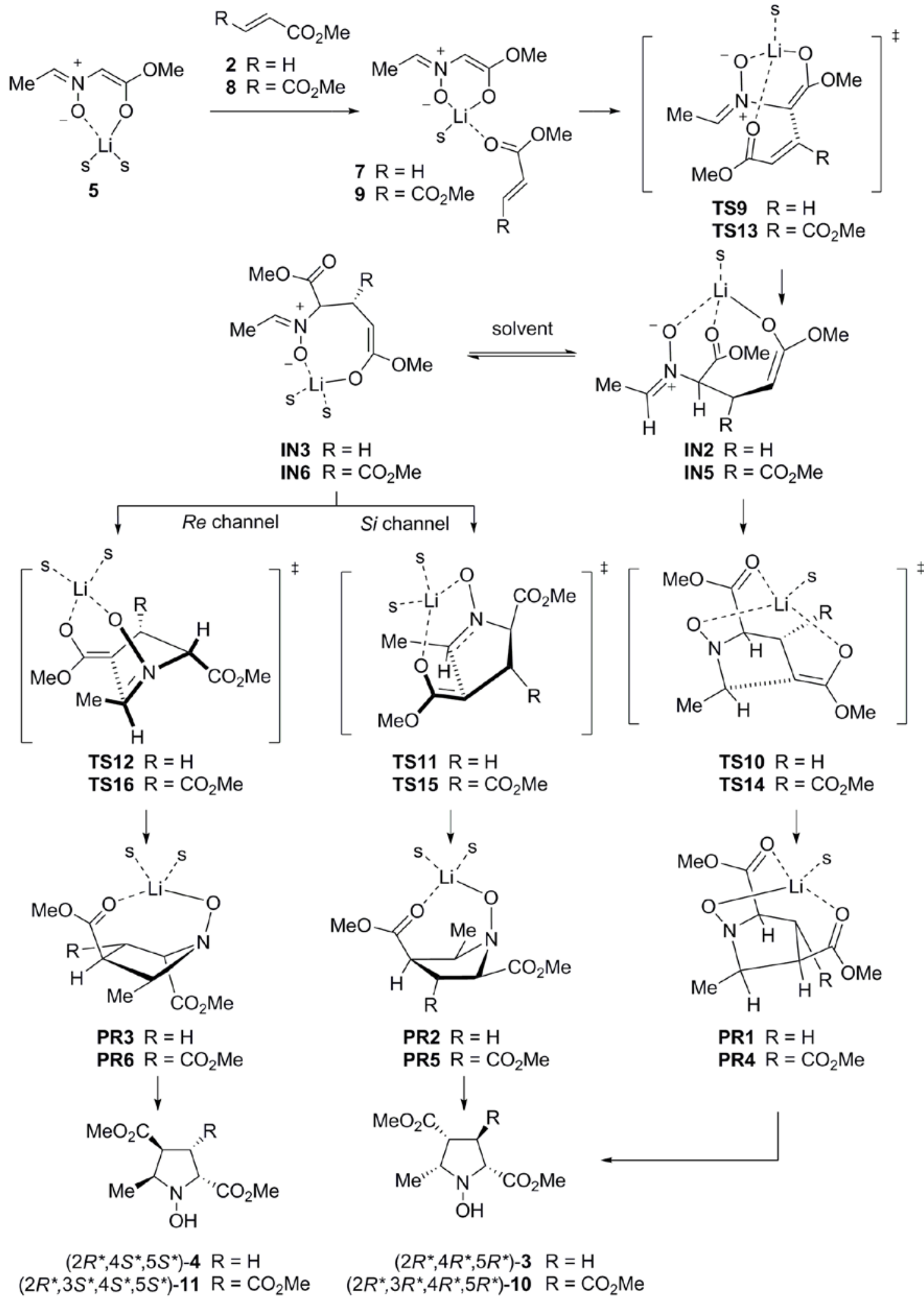

Scheme 5. Stepwise mechanisms for the cycloaddition of nitrone ylide 5 with methyl acrylate 2 and methyl furmarate $\mathbf{8}$. $\left(\mathrm{s}=\mathrm{Me}_{2} \mathrm{O}\right)$ 


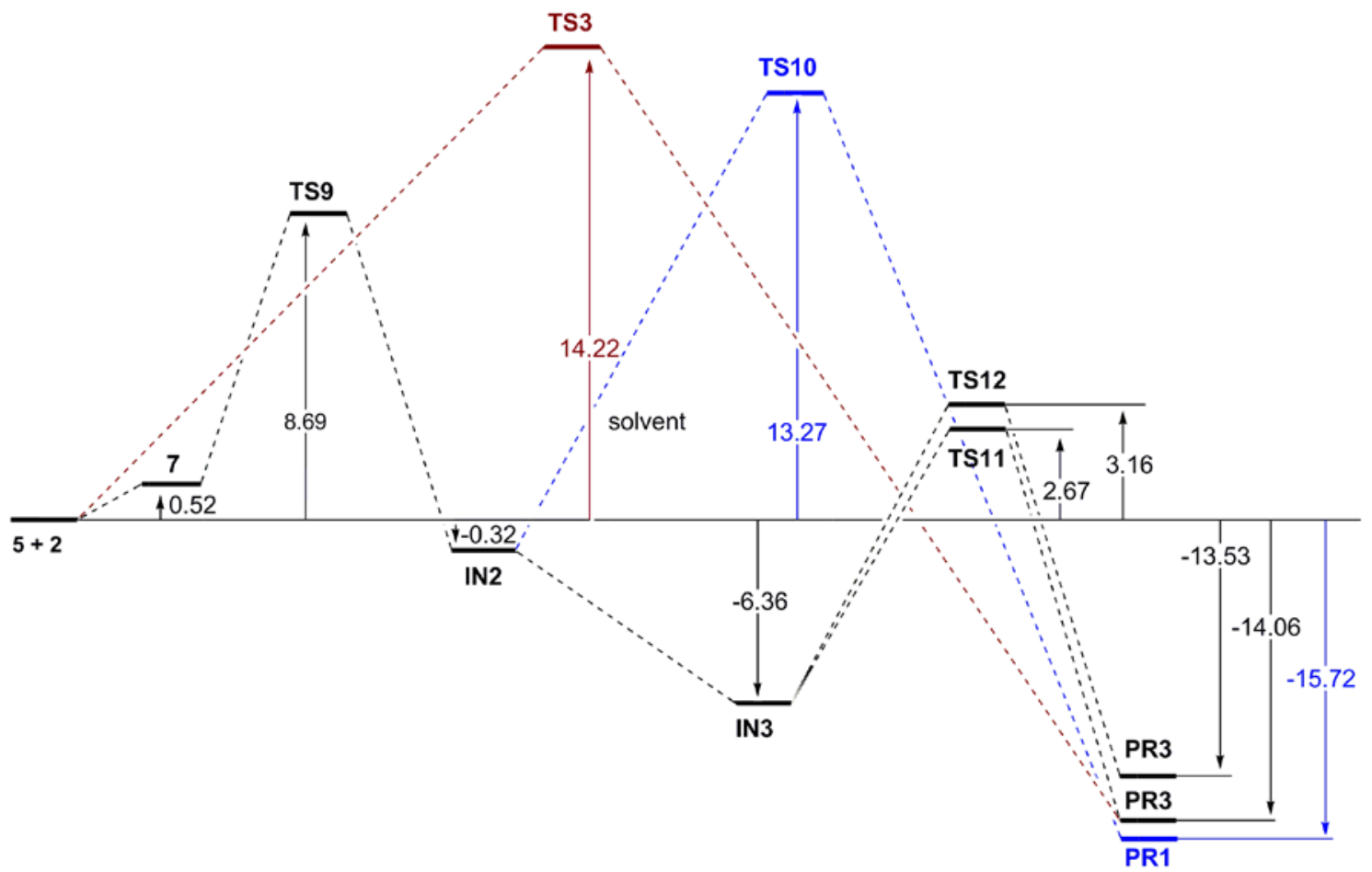

Figure 4. Energy diagram for the stepwise mechanisms corresponding to the cycloaddition of nitrone ylide 5 with methyl acrylate $\mathbf{2}$ (Scheme 5, R = H). Relative energy values are given in $\mathrm{kcal} / \mathrm{mol}$ and correspond to optimized points at PCM=THF/M06-2X/6-311+G(d,p) level.

The geometries of TS9 and TS10 are given in Figure 5. The length of forming C2-C3 bond in TS9 is $2.151 \AA$. Also in this case an interaction between C4 and C5 is observed, with a distance of $2.889 \AA$ A. Again the IRC analysis for TS9 confirmed that the final forward point of this step was IN2 (see supporting) with a C2-C3 bond length of $1.585 \AA$ and a distance between C4 and C5 of $3.320 \AA$. The length of the forming C4-C5 bond in TS10 is $2.33 \AA$ in good agreement with those previously observed for intermolecular Mannich-type additions of lithium ester enolates to nitrones. ${ }^{8 \mathrm{e}}$ The coordination of the lithium atom to the three oxygen atoms during the rate-limiting step is the responsible of the all-cis relative configuration observed experimentally for the major adduct 3. However, such coordination does not allow any other approach of the 
ylide to the nitrone moiety because of the rigidity of the system. Consequently, the path involving TS10 cannot justify the obtention of the minor adduct $\mathbf{4}$ predicting a reaction completely stereoselective (Figure 4, blue path). On the other hand, intermediate IN3 has enough flexibility for considering two competitive approaches of the enolate by the two faces of the nitrone. Both IN2 and IN3 are connected by a solvent molecule exchange, the formation of IN3 from IN2 being exothermic by $6.04 \mathrm{kcal} / \mathrm{mol}$. This difference in energy is justified by the incorporation of an additional solvent molecule (in agreement with previous studies) ${ }^{38}$ liberating strain in the lithium coordination.

The intermediate IN3 evolves through diastereomeric Si and Re channels to give adducts PR2 and PR3, respectively. This pathway is in full agreement with the observed experimental results since it predicts the two observed adducts having $\left(2 R^{*}, 4 R^{*}, 5 R^{*}\right)$ and $\left(2 R^{*}, 4 S^{*}, 5 S^{*}\right)$ configurations. The geometries of the corresponding TS11 and TS12 are given in Figure 5. The lengths of the forming C4-C5 bond at TS11 and TS12 are 2.299 and $2.329 \AA$, respectively. The analysis of the free activation energies revealed that TS11 is favored by $0.49 \mathrm{kcal} / \mathrm{mol}$. The energy barriers are 10.11 and $10.60 \mathrm{kcal} / \mathrm{mol}$ lower in energy than the associated with the direct conversion of IN2 into PR1 via TS10. The formation of IN3 leads to a competitive obtention of $\mathbf{3}$ and 4 predicting diastereomeric mixtures as it occurs experimentally. By considering this path, i.e. interconversion of IN2 into IN3, the rate-determining step corresponds to that in which the first C2-C3 bond is formed (TS9). 


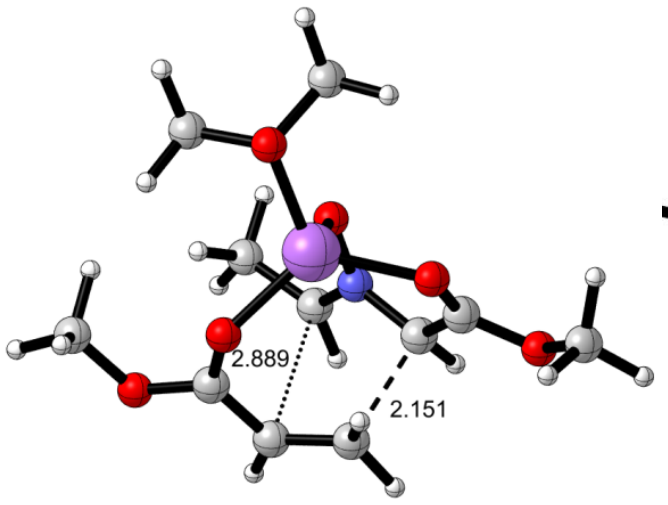

TS9

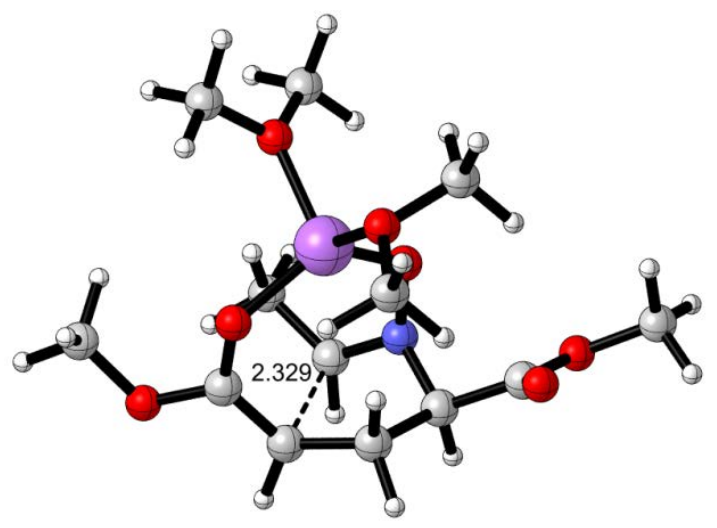

TS11

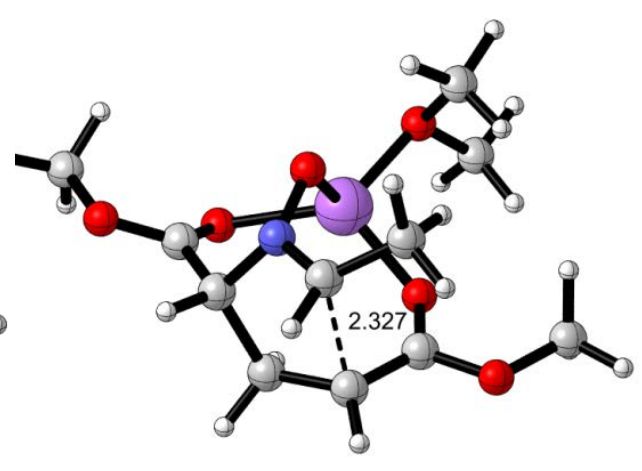

TS10

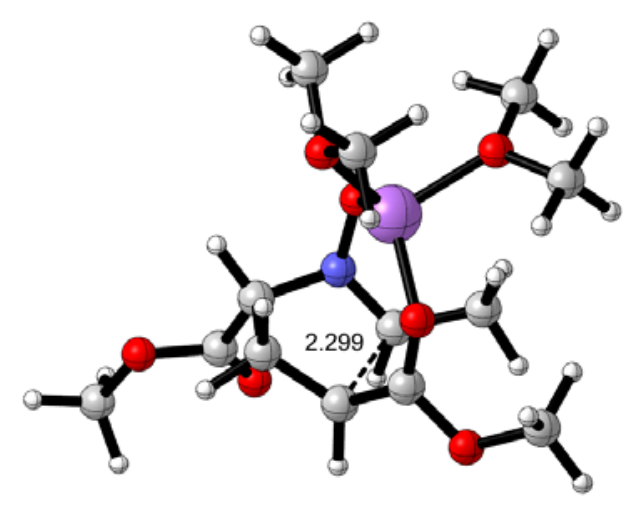

TS12

Figure 5. Geometry of transition structures TS9-TS12 at PCM=THF/M06-2X/6$311+\mathrm{G}(\mathrm{d}, \mathrm{p})$ level.

From the several levels of theory studied only those using the Thrular's functional M06-2X provided energy values in agreement with the experimental findings for an exergonic reaction. Energy calculations with B3LYP functional (B3LYP/6-31+G(d)) predict and endergonic reaction. On the other hand both calculations in the absence of solvent (M06-2X/6-31+G(d)) and fully optimized 3Z calculations (PCM=THF/M062X/6-311+G(d,p)) using the Thrular's functional afforded coherent results with the experimental observations. The differences between functionals are also evidenced in single point calculations using B3LYP geometries. Whereas B3LYP functional (PCM=THF/B3LYP/6-311+G(d,p)//B3LYP/6-31+G(d)) predicts again an endergonic 
reaction, M06-2X functional (PCM=THF/M06-2X/6-311+G(d,p)//B3LYP/6-31+G(d)

provides quite similar results to those obtained with the highest level of theory employed (see Supporting).

Cycloaddition with disubstituted alkenes. The reaction of nitrone ylides with methyl fumarate $\mathbf{8}$ afforded an only diastereomer in all cases studied. ${ }^{20}$ The obtained isomers have $\left(2 R^{*}, 3 R^{*}, 4 R^{*}, 5 R^{*}\right)$ configuration (Scheme 5 , compound 10). In order to evaluate if the same mechanism operating for methyl acrylate $\mathbf{2}$ could be valid for disubstituted alkenes we studied the reaction following the same methodology described in the preceding section. Calculations at PCM=THF/M06-2X/6-311+G(d,p) level of all the stationary points illustrated in Scheme $5\left(\mathrm{R}=\mathrm{CO}_{2} \mathrm{Me}\right)$ were carried out. In addition, the corresponding transition structures equivalent to TS1 and TS3 were also located showing in both cases higher energy values than TS13, the corresponding transition structure for the initial Michael addition (for details see supporting information). A full energy diagram is given in Figure 6. The geometry of TS13 is given in Figure 7. The length of the forming C2-C3 bond is $2.085 \AA$ and an interaction between C4 and C5 is observed with a distance of $2.749 \AA$. The IRC analysis of TS13 led to the same conclusion that in the case of TS9 for methyl acrylate, the final forward point being IN5. Thus, also in the case of methyl fumarate the reaction follows a stepwise mechanism. However, some important differences are appreciated in the energy diagram illustrated in Figure 6. The formation of the first intermediate IN5 through the initial Michael addition is the rate-limiting step of the reaction as in the case of methyl acrylate. The energy barrier is $5.34 \mathrm{kcal} / \mathrm{mol}$. The corresponding intermediate IN5 is $3.26 \mathrm{kcal} / \mathrm{mol}$ below the reagents. Also, the intermediate IN6 is thermodynamically favored by $4.78 \mathrm{kcal} / \mathrm{mol}$. However, contrary to that observed for methyl acrylate, the 
transition structure TS14 coming from the monosolvated intermediate IN5 is lower in energy than the transition structures TS15 and TS16 coming from the disolvated IN6. In consequence, for the reaction of nitrone ylide $\mathbf{5}$ with methyl fumarate $\mathbf{8}$ the preferred pathway is that in which the lithium atom is tricoordinated only being possible the formation of adduct $\mathbf{1 0}$ (Figure 6, black path). These results fully explain the completed stereoselectivity observed experimentally. The geometries of TS14, TS15 and TS16 are given in Figure 7 being very similar to those found for methyl acrylate (TS10-TS12). The length of the forming C4-C5 bond in TS14, TS15 and TS16 is 2.312, 2.312 and 2.310 Á, respectively.

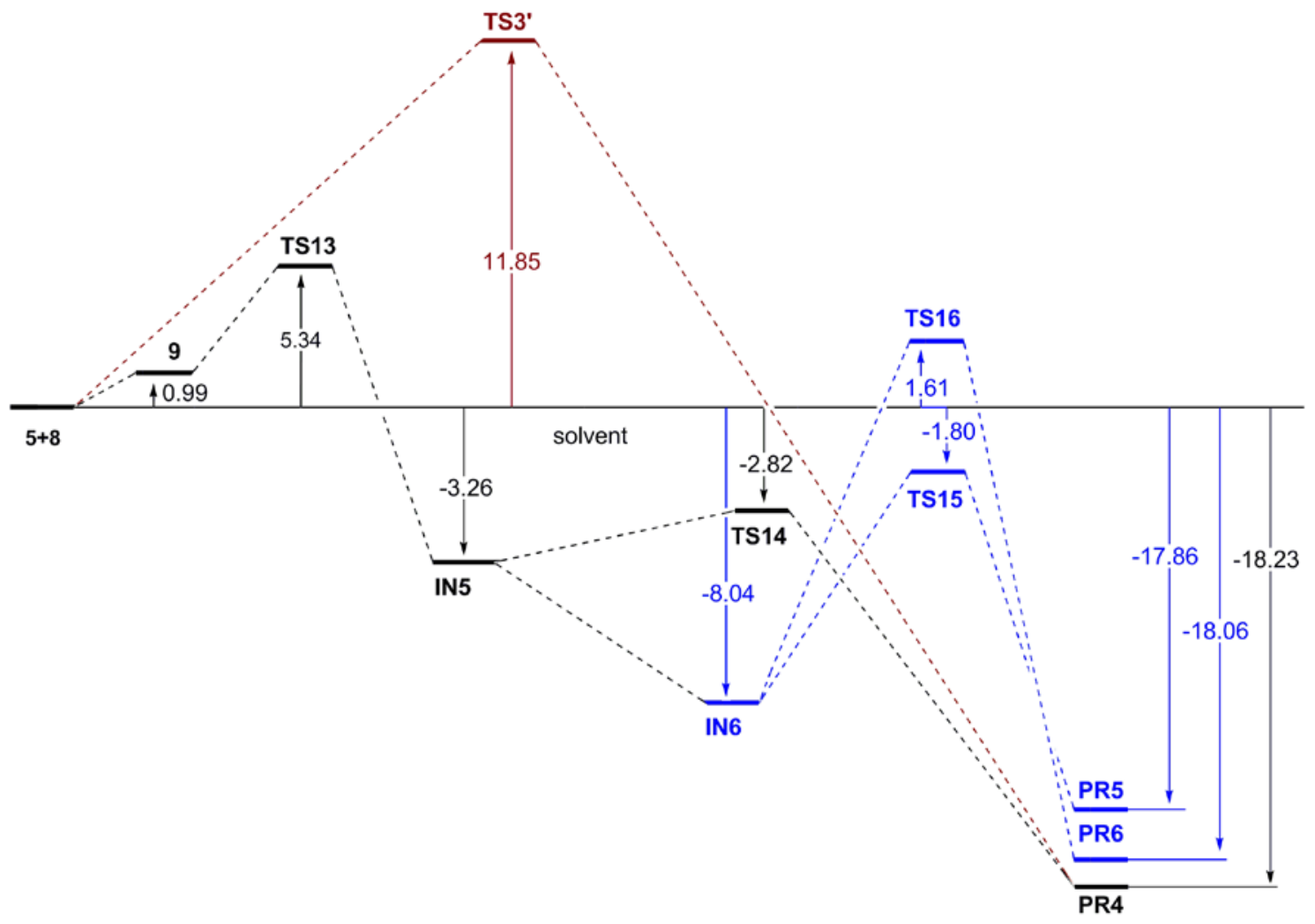

Figure 6. Energy diagram for the stepwise mechanisms corresponding to the cycloaddition of nitrone ylide 5 with methyl fumarate $\mathbf{8}$ (Scheme $5, \mathrm{R}=\mathrm{CO}_{2} \mathrm{Me}$ ) Relative energy values are given in $\mathrm{kcal} / \mathrm{mol}$ and correspond to optimized points at PCM=THF/M06-2X/6-311+G(d,p) level. 


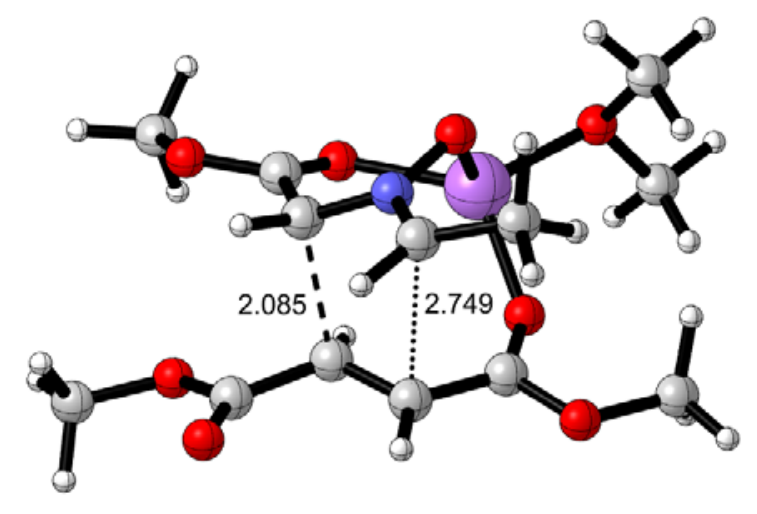

TS13

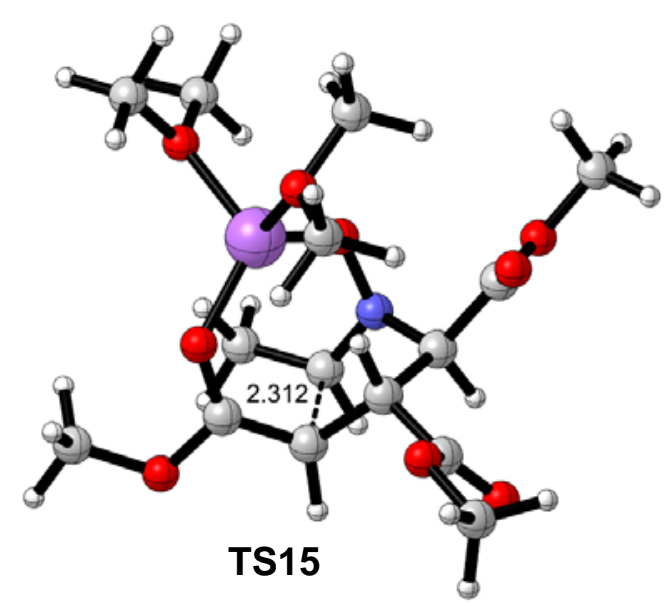

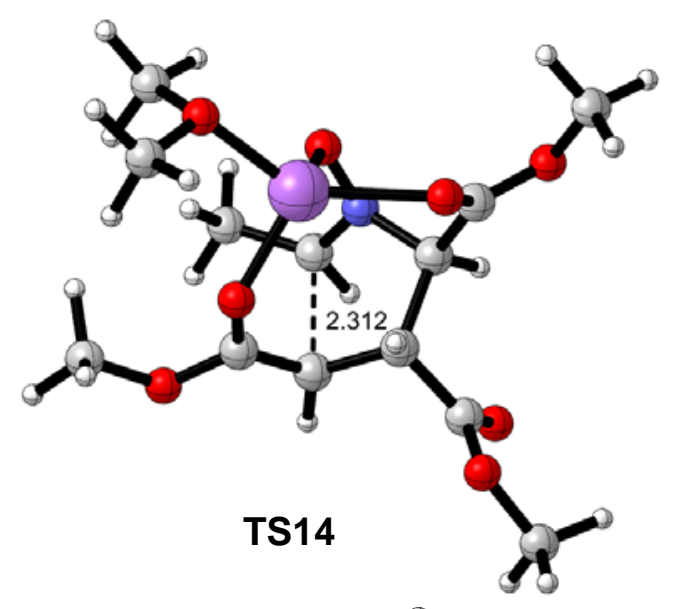

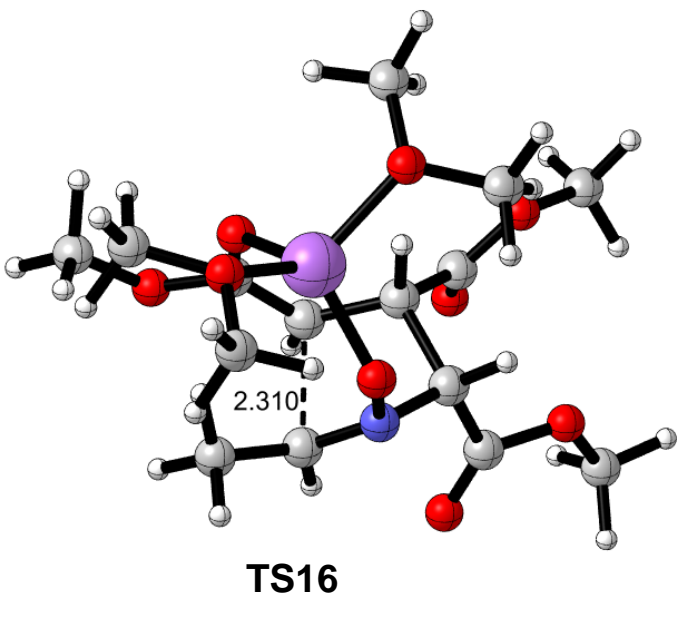

Figure 7. Geometry of transition structures TS13-TS16 at PCM=THF/M06-2X/6$311+G(d, p)$ level.

The reaction between $\mathbf{5}$ and methyl maleate $\mathbf{1 2}$ also afforded an only diastereomer having $\left(2 R^{*}, 3 S^{*}, 4 R^{*}, 5 R^{*}\right)$ configuration. However, it presents notable differences with respect to the reaction between $\mathbf{5}$ and $\mathbf{8}$ as a consequence of the $Z$-configuration of the double bond. The presence of a second ester unit oriented towards the lithium atom causes that additional models of coordination could be possible. The considered stepwise mechanisms are illustrated in Scheme 6 and a full diagram is given in Figure 8. We have also located TS3', the lowest transition structure corresponding to a direct approach between 5 and 12. The energy barrier for such an approach is $10.77 \mathrm{kcal} / \mathrm{mol}$ (Figure 8, red pathway). The first step of the reaction is similar to that observed for 2 
and $\mathbf{8}$ since coordination of the carbonyl oxygen at $\beta$-position is required to promote the Michael addition. Thus, complex 13 evolves towards intermediate IN7 through TS17. The energy barrier for this transformation is $7.8 \mathrm{kcal} / \mathrm{mol}$ since $\mathbf{1 3}$ is $1.29 \mathrm{kcal} / \mathrm{mol}$ above the reagents (nitrone ylide and alkene). The geometry of TS17 is given in Figure 9. The forming bond C2-C3 is $2.085 \AA$ and the interaction between C4 and C5 afforded a distance of $2.749 \AA$ Á between those atoms. The IRC analysis of TS17 clearly demonstrates that it connects $\mathbf{1 3}$ with IN7. This intermediate can be transformed into PR7, the precursor of the only obtained $\left(2 R^{*}, 3 S^{*}, 4 R^{*}, 5 R^{*}\right)$-isomer, through TS18 with an energy barrier of $4.79 \mathrm{kcal} / \mathrm{mol}$. Notably, PR7 is the most stable complex in which no solvent molecules are coordinated to the lithium atom. Other complexes having one solvent molecule coordinated showed to be less stable. The forming bond C4-C5 in TS18 is 2.304 Á (Figure 9). 


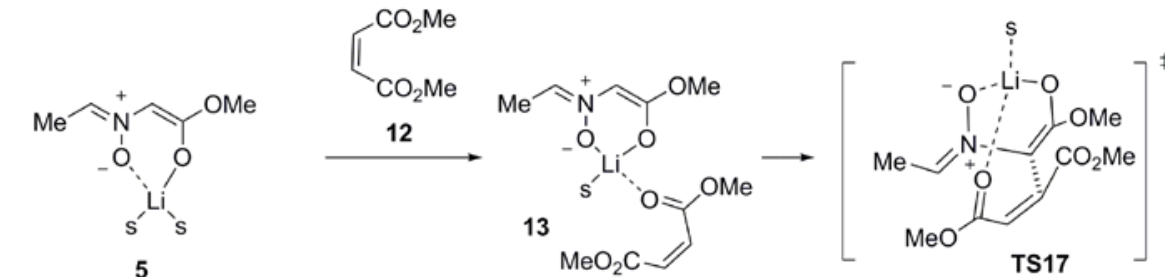

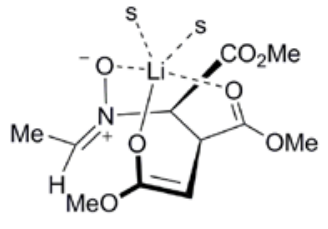

IN9

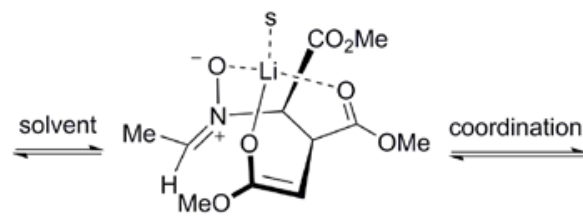

IN8

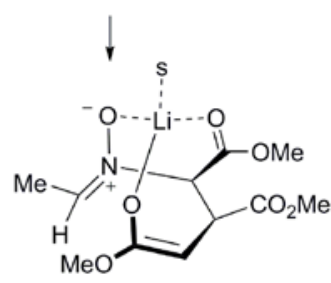

IN7

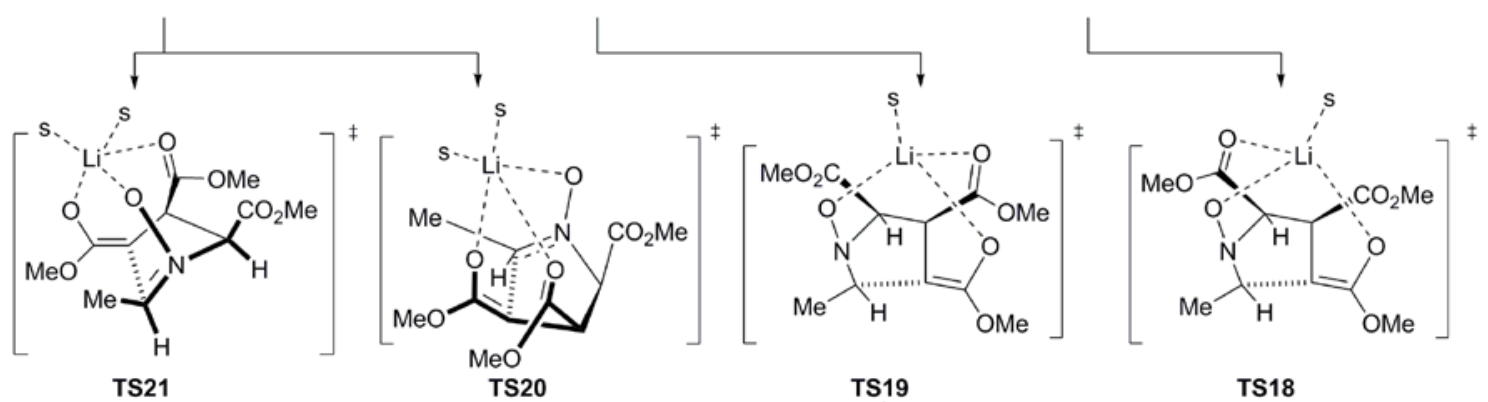

$\checkmark$

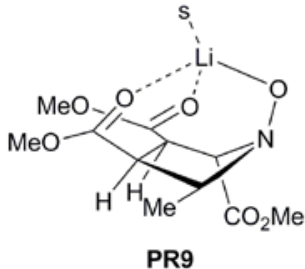
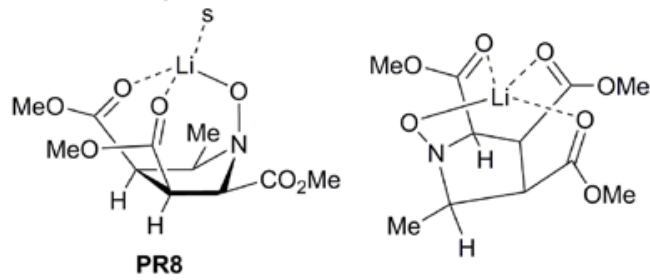

PR7

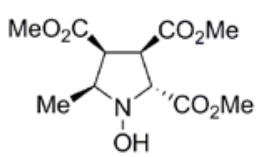

$\mathrm{MeO}_{2} \mathrm{C}$,

$\downarrow$

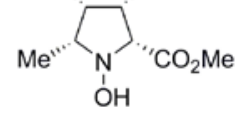

$\left(2 R^{\star}, 3 S^{*}, 4 R^{\star}, 5 R^{\star}\right)-14$

Scheme 6. Stepwise mechanisms for the cycloaddition between nitrone ylide $\mathbf{5}$ and methyl maleate 12. $\left(\mathrm{s}=\mathrm{Me}_{2} \mathrm{O}\right)$ 


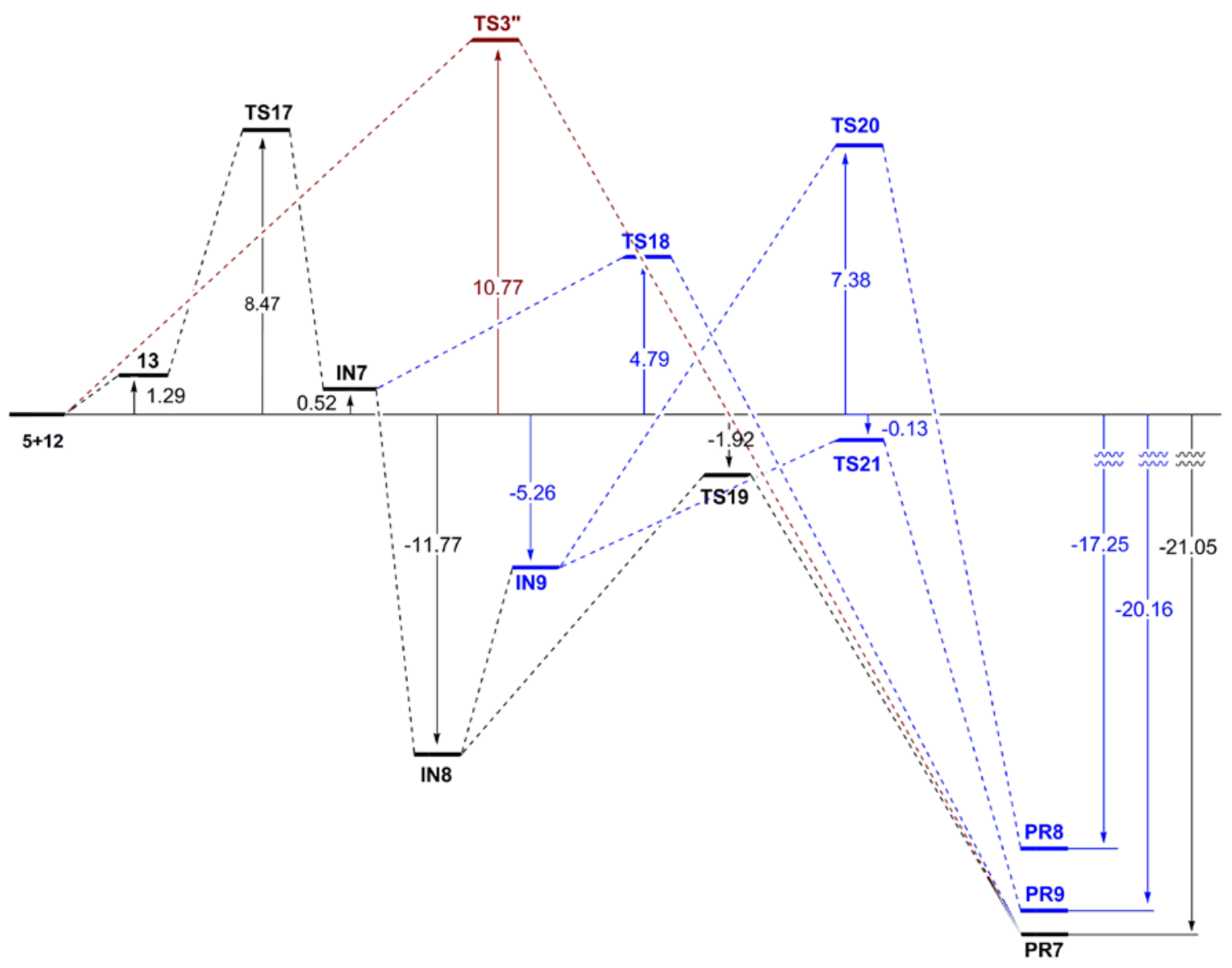

Figure 8. Energy diagram for the stepwise mechanisms corresponding to the cycloaddition of nitrone ylide 5 with methyl maleate 12. Relative energy values are given in $\mathrm{kcal} / \mathrm{mol}$ and correspond to optimized points at PCM=THF/M06-2X/6$311+G(d, p)$ level. 

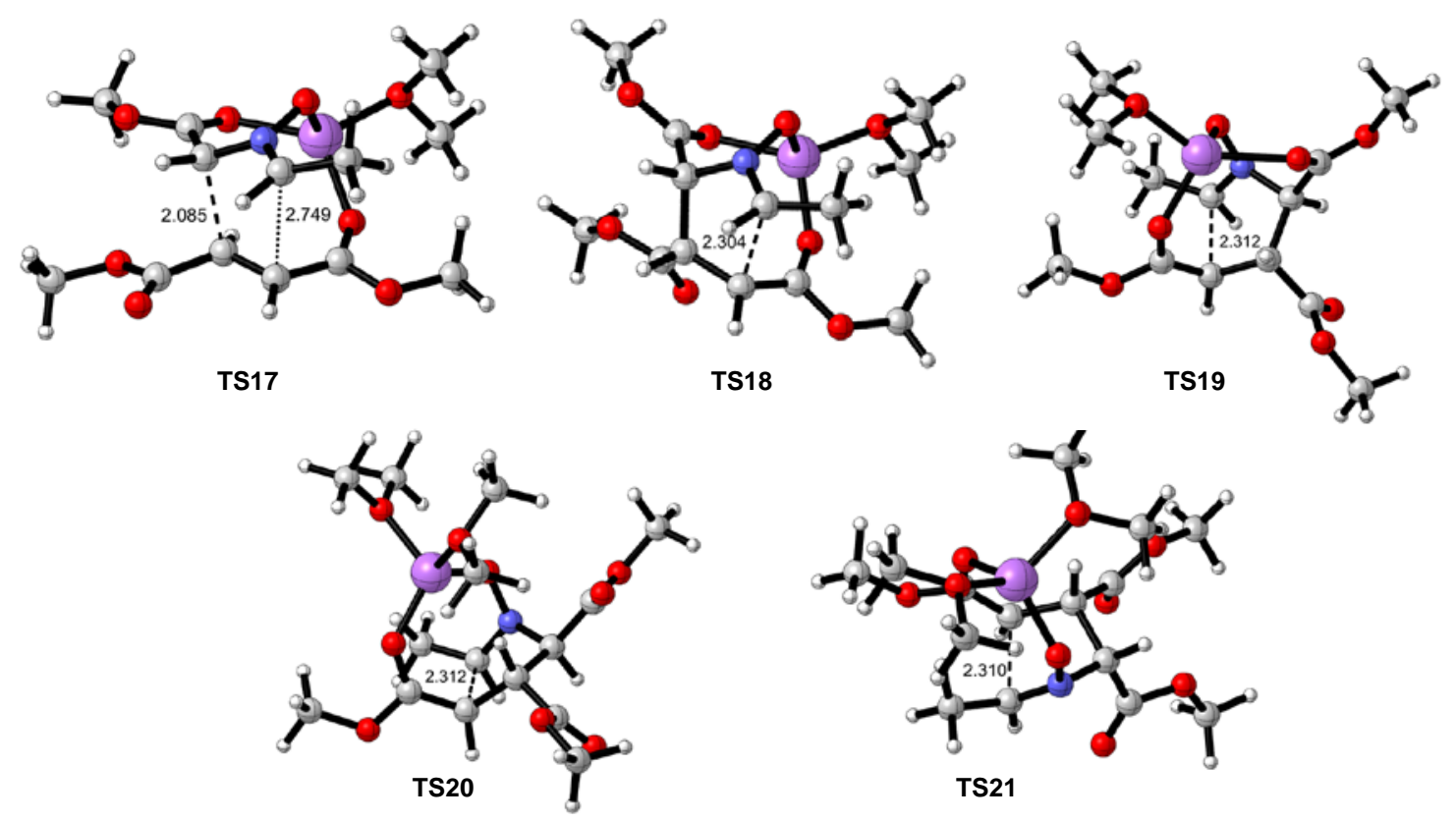

Figure 9. Geometry of transition structures TS17-TS21 at PCM=THF/M06-2X/6311+G(d,p) level.

Coordination in IN7 exerts a high strain; indeed, this intermediate is $0.52 \mathrm{kcal} / \mathrm{mol}$ above the reagents. On the other hand, exchange of coordination with the ester at $\beta$ position of the nitrone nitrogen afforded the considerable more stable IN8, which is $11.77 \mathrm{kcal} / \mathrm{mol}$ below the reagents. IN8 can also be converted into PR7 through TS19 which is $1.92 \mathrm{kcal} / \mathrm{mol}$ below the reagents. The forming bond C4-C5 in TS19 is 2.312 Á (Figure 9). As in the case of methyl fumarate and acrylate we also considered exchange of the ester coordination by a solvent molecule. However, in this case the relative configuration of the ester group at $\beta$-position of the nitrone nitrogen favors the proximity to the lithium atom and pentacoordinated lithium is obtained as the most stable complex where two molecules of solvent are considered. Coordination of the ester at $\alpha$-position of the nitrone nitrogen is disfavored as illustrated in IN7. The corresponding intermediate IN9 is less stable than IN8, being $5.26 \mathrm{kcal} / \mathrm{mol}$ below the reagents. We considered the two possible Mannich-type attacks in IN9 leading to PR8 
and PR9 through TS20 and TS21, respectively. Whereas TS21 leading to the not experimentally observed isomer $\mathbf{1 5}$ is $0.13 \mathrm{kcal} / \mathrm{mol}$ below the reagents, TS20 leading to the obtained $\mathbf{1 4}$ is found to be considerably less stable being $7.38 \mathrm{kcal} / \mathrm{mol}$ above the reagents. The lengths of forming bonds C4-C5 in TS20 and TS21 are 2.312 and 2.310 Á, respectively (Figure 9).

From these results it becomes evident that in the case of methyl maleate the preferred route is the formation of IN8 through TS17 and IN7, followed by transformation into PR7 through TS19 (Figure 8, black path). The rate-limiting step of the process is the first Michael attack (TS17) with an energy barrier of $8.47 \mathrm{kcal} / \mathrm{mol}$ and the further evolution through the only possible TS19 fully justifies the obtention of an only isomer with all-cis configuration.

\section{Conclusions}

The molecular mechanisms for the reaction of nitrone ylides with electrondeficient alkenes have been investigated by DFT methods. Both concerted and stepwise mechanisms have been considered. In all cases, the reactions showed to be stepwise consisting of an initial Michael attack followed by an intramolecular Mannich-type reaction. Coordination of the lithium atom to the nitrone oxygen and carbonyl oxygen atoms in an early step of the reaction promotes both steps efficiently. The reaction with methyl acrylate can take place through two intermediates associated to di- and tricoordinated lithium models. The tricoordinated model only can lead to the all-cis $\left(2 R^{*}, 4 R^{*}, 5 R^{*}\right)$ isomer, whereas the dicoordinated model can lead to isomers having $\left(2 R^{*}, 4 R^{*}, 5 R^{*}\right)$ and $\left(2 R^{*}, 4 S^{*}, 5 S^{*}\right)$ configurations. Even though both models might be competitive , the calculations correctly predict the experimental observations in which the minor $\left(2 R^{*}, 4 S^{*}, 5 S^{*}\right)$ isomer is also obtained. On the other hand, for the reaction of 
nitrone ylides with methyl fumarate and maleate, calculations predict the tricoordinated model as the preferred one thus explaining that only one isomer is obtained, in full agreement with the experimental findings. Several levels of theory using B3LYP and M06-2X functionals have been employed and only those using the Thrular's functional provided successful results. Also, the use of $3 Z$ basis sets was crucial for the identification of the stepwise mechanism by means of IRC analyses.

\section{Acknowledgments}

We thank for their support of our programs: the Spanish Ministry of Science and Innovation (Madrid, Spain. Project CTQ2010-19606) and the Government of Aragon (Zaragoza, Spain). A.D.-M. also thanks the Government of Aragon for a pre-doctoral fellowship. The authors thankfully acknowledge the resources from the supercomputers Terminus and Memento, technical expertise and assistance provided by the Institute for Biocomputation and Physics of Complex Systems (BIFI, University of Zaragoza).

\section{Supporting Information}

Geometries of transition structures TS1-TS8; absolute (hartrees) and relative (kcal/mol) electronic and free energies at B3LYP/6-31+G(d), M06-2X/6-31+G(d), PCM=THF/B3LYP/6-311+G(d) / B3LYP/6-31+G(d), PCM=THF/ M06-2X /6311+G(d) / B3LYP/6-31+G(d) and PCM=THF/M06-2X/6-311+G(d,p) levels of theory; energy diagrams; IRC analyses and Cartesian coordinates of optimized structures. This material is available free of charge via the Internet at http:// pubs.acs.org 


\section{References and Notes}

(1) According to IUPAC (Gold Book) a pericyclic reaction is a process "in which concerted reorganization of bonding takes place throughout a cyclic array of continuously bonded atoms". See: Muller, P. Pure Appl. Chem. 1994, 66, 10771184, on page 1150.

(2) (a) Firestone, R. A. Heterocycles 1987, 25, 61-64. (b) Firestone, R. A. J. Org. Chem. 1968, 33, 2285-2290. (c) Huisgen, R. J. Org. Chem. 1976, 41, 403-419. (d) Firestone, R. A. Tetrahedron 1977, 33, 3009-3039. (e) Scaiano, J. C.; Wintgens, V.; Haider, K.; Berson, J. A. J. Am. Chem. Soc. 1989, 111, 8732-8733. (f) Li, Y.; Padias, A. B.; Hall, H. K., Jr. J. Org. Chem. 1993, 58, 7049-7058. (g) Klaerner, F.-G.; Krawczyk, B.; Ruster, V.; Deiters, U. K. J. Am. Chem. Soc. 1994, 116, 7646-7657. (h) Bradley, A. Z.; Kociolek, M. G.; Johnson, R. P. J. Org. Chem. 2000, 65, 7134-7138.

(3) (a) de Echaguen, C. O.; Ortuno, R. M. Tetrahedron Lett. 1995, 36, 749-752. (b) Branchadell, V.; Font, J.; Moglioni, A. G.; Ochoa de Echagueen, C.; Oliva, A.; Ortuno, R. M.; Veciana, J.; Vidal-Gancedo, J. J. Am. Chem. Soc. 1997, 119, 999210003. (c) Lakhdar, S.; Terrier, F.; Vichard, D.; Berionni, G.; El Guesmi, N.; Goumont, R.; Boubaker, T. Chem. Eur. J. 2010, 16, 5681-5690. (d) NavarroVazquez, A.; Alonso-Gomez, J.-L.; Lugtenburg, J.; Cid, M.-M. Tetrahedron 2010, 66, 3855-3860.

(4) (a) Yu, Z.-X.; Caramella, P.; Houk, K. N. J. Am. Chem. Soc. 2003, 125, $15420-$ 15425. (b) Yu, Z.-X.; Houk, K. N. J. Am. Chem. Soc. 2003, 125, 13825-13830.

(5) (a) Wagenseller, P. E.; Birney, D. M.; Roy, D. J. Org. Chem. 1995, 60, 28532859. (b) Birney, D. M. J. Org. Chem. 1996, 61, 243-251. (c) Birney, D. M.; 
Ham, S.; Unruh, G. R. J. Am. Chem. Soc. 1997, 119, 4509-4517. (d) Birney, D. M. Curr. Org. Chem. 2010, 14, 1658-1668.

(6) Krenske, E. H.; He, S.; Huang, J.; Du, Y.; Houk, K. N.; Hsung, R. P. J. Am. Chem. Soc. 2013, 135, 5242-5245.

(7) Merino, P.; Roca-Lopez, D.; Caramella, P.; Tejero, T. Org. Biomol. Chem. 2014, 12, 517-525.

(8) (a) Krenske, E. H.; Houk, K. N.; Harmata, M. Org. Lett. 2010, 12, 444-447. (b) Wang, J.-M.; Li, Z.-M.; Wang, Q.-R.; Tao, F.-G. Int. J. Quantum Chem. 2012, 112, 809-822. (c) Gonzalez-James, O. M.; Kwan, E. E.; Singleton, D. A. J. Am. Chem. Soc. 2012, 134, 1914-1917. (d) Arroyo, P.; Picher, M. T.; Domingo, L. R. J. Mol. Struct. THEOCHEM 2004, 709, 45-52. (e) Diez-Martinez, A.; Tejero, T.; Merino, P. Tetrahedron: Asymmetry 2010, 21, 2934-2943. (f) Lan, Y.; Houk, K. N. J. Am. Chem. Soc. 2010, 132, 17921-17927. (g) Merino, P.; Tejero, T. Synlett 2011, $1965-1977$.

(9) (a) Arno, M.; Picher, M. T.; Domingo, L. R.; Andres, J. Chem. Eur. J. 2004, 10, 4742-4749. (b) Domingo, L. R.; Picher, M. T.; Arroyo, P.; Saez, J. A. J. Org. Chem. 2006, 71, 9319-9330. (c) Gassman, P. G.; Gorman, D. B. J. Am. Chem. Soc. 1990, 112, 8624-8626. (d) Shapiro, N. D.; Toste, F. D. J. Am. Chem. Soc. 2008, 130, 9244-9245. (e) Domingo, L. R.; Arno, M.; Merino, P.; Tejero, T. Eur. J. Org. Chem. 2006, 3464-3472.

(10) (a) Houk, K. N.; Li, Y.; Storer, J.; Raimondi, L.; Beno, B. J. Chem. Soc., Faraday Trans. 1994, 90, 1599-1604. (b) Ajaz, A.; Bradley, A. Z.; Burrell, R. C.; Li, W. H. H.; Daoust, K. J.; Bovee, L. B.; DiRico, K. J.; Johnson, R. P. J. Org. Chem. 2011, 76, 9320-9328. (c) Qiao, Y.; Chu, T.-S. J. Org. Chem. 2011, 76, 3086-3095. (d) Saito, T.; Nishihara, S.; Kataoka, Y.; Nakanishi, Y.; Kitagawa, Y.; Kawakami, T.; 
Yamanaka, S.; Okumura, M.; Yamaguchi, K. J. Phys. Chem. A 2010, 114, 1211612123. (e) Braida, B.; Walter, C.; Engels, B.; Hiberty, P. C. J. Am. Chem. Soc. 2010, 132, 7631-7637. (f) Xu, L.; Doubleday, C. E.; Houk, K. N. Angew. Chem., Int. Ed. 2009, 48, 2746-2748. (g) Sakai, S.; Nguyen, M. T. J. Phys. Chem. A 2004, 108, 9169-9179. (h) Domingo, L. R.; Arno, M.; Contreras, R.; Perez, P. J. Phys. Chem. A 2002, 106, 952-961. (i) Eichberg, M. J.; Houk, K. N.; Lehmann, J.; Leonard, P. W.; Maerker, A.; Norton, J. E.; Sawicka, D.; Vollhardt, K. P. C.; Whitener, G. D.; Wolff, S. Angew. Chem., Int. Ed. 2007, 46, 6894-6898. (j) Fernandez, I.; Cossio, F. P.; de Cozar, A.; Lledos, A.; Mascarenas, J. L. Chem. Eur. J. 2010, 16, 12147-12157.

(11) (a) Yao, Z.-K.; Yu, Z.-X. J. Am. Chem. Soc. 2011, 133, 10864-10877. (b) Lage, M. L.; Fernandez, I.; Sierra, M. A.; Torres, M. R. Org. Lett. 2011, 13, 2892-2895. (c) Kohmoto, S.; Kobayashi, T.; Minami, J.; Ying, X.; Yamaguchi, K.; Karatsu, T.; Kitamura, A.; Kishikawa, K.; Yamamoto, M. J. Org. Chem. 2001, 66, 66-73. (d) Penoni, A.; Palmisano, G.; Zhao, Y.-L.; Houk, K. N.; Volkman, J.; Nicholas, K. M. J. Am. Chem. Soc. 2009, 131, 653-661. (e) Nakamura, T.; Takegami, A.; Abe, M. J. Org. Chem. 2010, 75, 1956-1960.

(12) Domingo, L. R. J. Org. Chem. 1999, 64, 3922-3929.

(13) Domingo, L. R.; Chamorro, E.; Perez, P. Lett. Org. Chem. 2010, 7, 432-439.

(14) (a) Freeman, F.; Dang, P.; Huang, A. C.; Mack, A.; Wald, K. Tetrahedron Lett. 2005, 46, 1993-1995. (b) Das, T. K.; Banerjee, M. J. Phys. Org. Chem. 2010, 23, 148-155. (c) Chandraprakash, K.; Sankaran, M.; Uvarani, C.; Shankar, R.; Ata, A.; Dallemer, F.; Mohan, P. S. Tetrahedron Lett. 2013, 54, 3896-3901.

(15) He, L.; Chen, X.-H.; Wang, D.-N.; Luo, S.-W.; Zhang, W.-Q.; Yu, J.; Ren, L.; Gong, L.-Z. J. Am. Chem. Soc. 2011, 133, 13504-13518. 
(16) Vivanco, S.; Lecea, B.; Arrieta, A.; Prieto, P.; Morao, I.; Linden, A.; Cossio, F. P. J. Am. Chem. Soc. 2000, 122, 6078-6092.

(17) Najera, C.; Retamosa, M. d. G.; Martin-Rodriguez, M.; Sansano, J. M.; de Cozar, A.; Cossio, F. P. Eur. J. Org. Chem. 2009, 5622-5634.

(18) (a) Hernandez-Toribio, J.; Arrayas, R. G.; Carretero Juan, C. J. Am. Chem. Soc. 2008, 130, 16150-16151. (b) Hernandez-Toribio, J.; Arrayas, R. G.; Carretero Juan, C. Chem. Eur. J. 2010, 16, 1153-1157.

(19) Castello, L. M.; Najera, C.; Sansano, J. M.; Larranaga, O.; de Cozar, A.; Cossio, F. P. Org. Lett. 2013, 15, 2902-2905.

(20) Merino, P.; Tejero, T.; Diez-Martinez, A.; Gueltekin, Z. Eur. J. Org. Chem. 2011, 2011, 6567-6573.

(21) (a) Merino, P. In Science of Synthesis; Pawda, A., Bellus, D., Eds.; Georg Thieme Verlag: Stuttgart-New York, 2004; Vol. 27, p 511-580. (b) Merino, P. In Science of Synthesis; Schaumann, E., Ed.; Georg Thieme Verlag: Stuttgart-New York, 2010; Vol. Update 2010/4, p 325-403.

(22) (a) Becke, A. D. J. Chem. Phys. 1993, 98, 5648-5652. (b) Lee, C.; Yang, W.; Parr, R. G. Phys. Rev. B 1988, 37, 785-789.

(23) Zhao, Y.; Truhlar, D. G. Acc. Chem. Res. 2008, 41, 157-167.

(24) (a) Ditchfield, R.; Hehre, W. J.; Pople, J. A. J. Chem. Phys. 1971, 54, 724-728. (b) Hehre, W. J.; Ditchfield, R.; Pople, J. A. J. Chem. Phys. 1972, 56, 2257-2261. (c) Hariharan, P. C.; Pople, J. A. Theor. Chim. Acta 1973, 28, 213-222. (d) Rassolov, V. A.; Pople, J. A.; Ratner, M. A.; Windus, T. L. J. Chem. Phys. 1998, 109, 12231229. (e) Rassolov, V. A.; Ratner, M. A.; Pople, J. A.; Redfern, P. C.; Curtiss, L. A. J. Comput. Chem. 2001, 22, 976-984. 
(25) (a) Schlegel, H. B. J. Comput. Chem. 1982, 3, 214218. (b) Schlegel, H. B. In Modern Electronic Structure Theory; Yarkony, D. R., Ed.; World Scientific Publishing: Singapore, 1994.

(26) (a) Fukui, K. J. Phys. Chem. 1970, 74, 4161-4163. (b) Fukui, K. Acc. Chem. Res. 1981, 14, 363-368.

(27) (a) González, C.; Schlegel, H. B. J. Phys. Chem. 1990, 94, 5523-5527. (b) González, C.; Schlegel, H. B. J. Chem. Phys. 1991, 95, 5853-5860.

(28) Wong, M. W.; Wiberg, K. B.; Frish, M. J. Chem. Phys. 1991, 95, 8991-8998.

(29) (a) Tomasi, J.; Persico, M. Chem. Rev. 1994, 94, 2027-2094. (b) Cossi, M.; Barone, V.; Cammi, R.; Tomasi, J. Chem. Phys. Lett. 1996, 255, 327-335. (c) Cossi, M.; Scalmani, G.; Rega, N.; Barone, V. J. Chem. Phys. 2002, 117, 43-54.

(30) (a) Domingo, L. R.; Gil, S.; Mestres, R.; Picher, M. T. Tetrahedron 1996, 52, 11105-11112. (b) Domingo, L. R.; Gil, S.; Mestres, R.; Picher, M. T. Tetrahedron 1995, 51, 7207-7214.

(31) Gaussian 09. Rev. A1. Frisch, M. J.; Trucks, G. W.; Schlegel, H. B.; Scuseria, G. E.; Robb, M. A.; Cheeseman, J. R.; Scalmani, G.; Barone, V.; Mennucci, B.; Petersson, G. A.; Nakatsuji, H.; Caricato, M.; Li, X.; Hratchian, H. P.; Izmaylov, A. F.; Bloino, J.; Zheng, G.; Sonnenberg, J. L.; Hada, M.; Ehara, M.; Toyota, K.; Fukuda, R.; Hasegawa, J.; Ishida, M.; Nakajima, T.; Honda, Y.; Kitao, O.; Nakai, H.; Vreven, T.; Montgomery, J., J. A.; Peralta, J. E.; Ogliaro, F.; Bearpark, M.; Heyd, J. J.; Brothers, E.; Kudin, K. N.; Staroverov, V. N.; Kobayashi, R.; Normand, J.; Raghavachari, K.; Rendell, A.; Burant, J. C.; Iyengar, S. S.; Tomasi, J.; Cossi, M.; Rega, N.; Millam, J. M.; Klene, M.; Knox, J. E.; Cross, J. B.; Bakken, V.; Adamo, C.; Jaramillo, J.; Gomperts, R.; Stratmann, R. E.; Yazyev, O.; Austin, A. J.; Cammi, R.; Pomelli, C.; Ochterski, J. W.; Martin, R. L.; 
Morokuma, K.; Zakrzewski, V. G.; Voth, G. A.; Salvador, P.; Dannenberg, J. J.;

Dapprich, S.; Daniels, A. D.; Farkas, Ö.; Foresman, J. B.; Ortiz, J. V.; Cioslowski, J.; Fox, D. J.; Gaussian, Inc., Wallingford CT,: 2009.

(32) Legault, C. Y.; CYLView, 1.0b, Universite de Sherbrooke, 2009. http://www.cylview.org

(33) In the original paper the absolute configurations were $\left(2 \mathrm{R}^{*}, 4 \mathrm{R}^{*}, 5 \mathrm{~S}^{*}\right)$ and $\left(2 \mathrm{R}^{*}, 4 \mathrm{~S}^{*}, 5 \mathrm{R}^{*}\right)$ because an aromatic substituent (instead of a methyl) is present at 5-position of the pyrrolidine ring

(34) For details on IRC analyses see supporting information

(35) Neumann, F.; Lambert, C.; Schleyer, P. v. R. J. Am. Chem. Soc. 1998, 120, 33573370.

(36) (a) Merino, P. Compt. Rend. Chim. 2005, 8, 775-788. (b) Merino, P.; Franco, S.; Merchan, F. L.; Tejero, T. Synlett 2000, 442-454.

(37) (a) Merino, P.; Tejero, T. Tetrahedron 2001, 57, 8125-8128. (b) Merino, P.; Mannucci, V.; Tejero, T. Tetrahedron 2005, 61, 3335-3347. (c) Delso, I.; Marca, E.; Mannucci, V.; Tejero, T.; Goti, A.; Merino, P. Chem. Eur. J. 2010, 16, 99109919.

(38) (a) Hayes, C. J.; Simpkins, N. S. Org. Biomol. Chem. 2013, 11, 8458-8462. (b) Abbotto, A.; Streitwieser, A.; Schleyer, P. v. R. J. Am. Chem. Soc. 1997, 119, 11255-11268. 